\title{
Towards Evaluative Framework of Multi-Sensory Landscape Elements
}

\author{
F. Ragab ${ }^{1}$, A. Eldin Sarhan², Y. Farghaly ${ }^{2}$
}

\begin{abstract}
Open spaces are not simply placing that people want to access; instead they are where many of the activities that fill people's lives occur. To experience these occupations, sensory stimuli must be emitted as a result of the use and interaction with the landscape elements in the surrounding environment. The engagement of more senses in the perceptual process of the user allows diverse experiences in the space, allowing variation of the users. However, most of the time, greater attention is given to the buildings and their design, ignoring outdoor spaces and their importance. Most open spaces are visually oriented, and this usually prevails over information obtained by the other senses. The main aim of this paper is to determine the importance of each landscape element in the multi-sensory design. This is achieved by a set of objectives, which study the user's perception of the open spaces, determine landscape elements and finally, indicate the sensory stimuli of each element and the human senses influenced by these stimuli.
\end{abstract}

KEYWORDS: sensory stimuli, landscape elements, surrounding environment, multi-sensory, human senses.

\section{INTRODUCTION}

The moving elements in a city, and in particular the people and their activities, are as important as the stationary physical elements. People are not only observers of the surroundings, but are part of them, with the other participants being the surrounding environmental elements. Nearly every sense is in operation, and the image is the composite of them all. The city is not only percieved by one user, but by millions of people of widely diverse class and character. [1] The relation between the user and the surrounding environment is created by the process of perception: the user, who is the main receiver, is first exposed to stimuli from the surrounding physical environment, containing human beings, non-human beings, built environment and climate, which is seen as the main emitter, before any serious attention may be given, as shown in figure 1. This space, once experienced by the user, becomes a place. [2]

1Associate Professor, Architectural Engineering \& Environmental Design Department, College of Engineering and Technology, AASTMT.

2Professor, Architectural Engineering \&Environmental Design Department, College of Engineering and Technology, AASTMT. 3 Teaching assistant, Architecture Engineering \& Environmental Design Department, Arab Academy for Science, Technology and Maritime Transport, Abukir Campus, Alexandria 


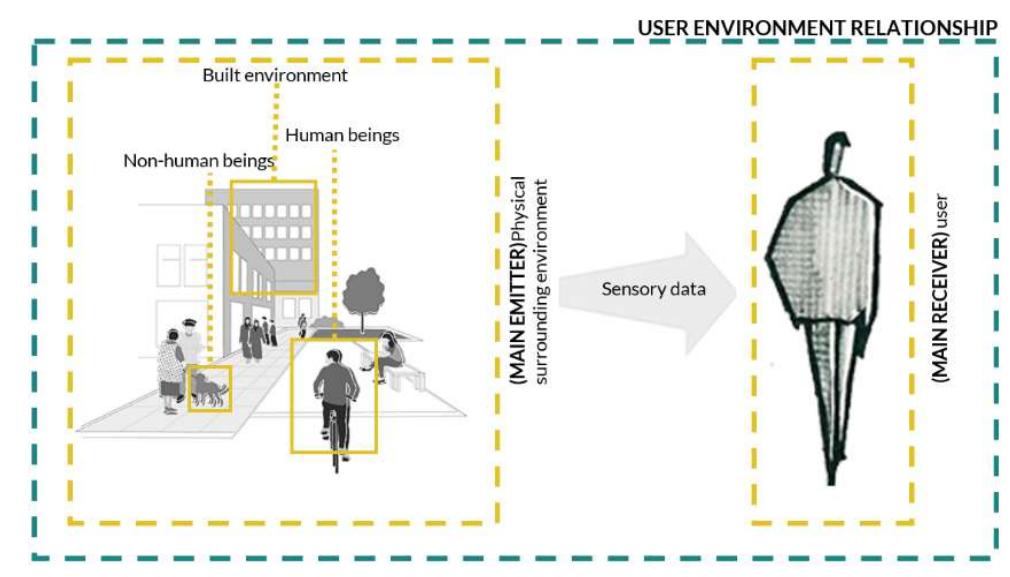

\section{LITERATURE REVIEW}

\subsection{PERCEPTUAL PROCESS}

Perception allows us to experience the surrounding world. The basic assumption is that the world around us must be filtered by our senses. [3] The perceptual process is a sequence of processes that work together to determine our experiences and reactions to stimuli in the surrounding environment. It does not only create our experience of the world, but also allows us to act within the surrounding environment. Hence, the perceptual process generally occurs between two main elements, which are the surrounding environment and the user. The user's perception is essentially divided into three main stages, as shown in figure 2: sensation which is the initial interaction between the user and the environment, followed by perception and cognition, which are totally dependent on the user's individual and cultural aspects, and finally, experience and action, which is how users experience and react to the stimulus gained from the surrounding environment. [2]

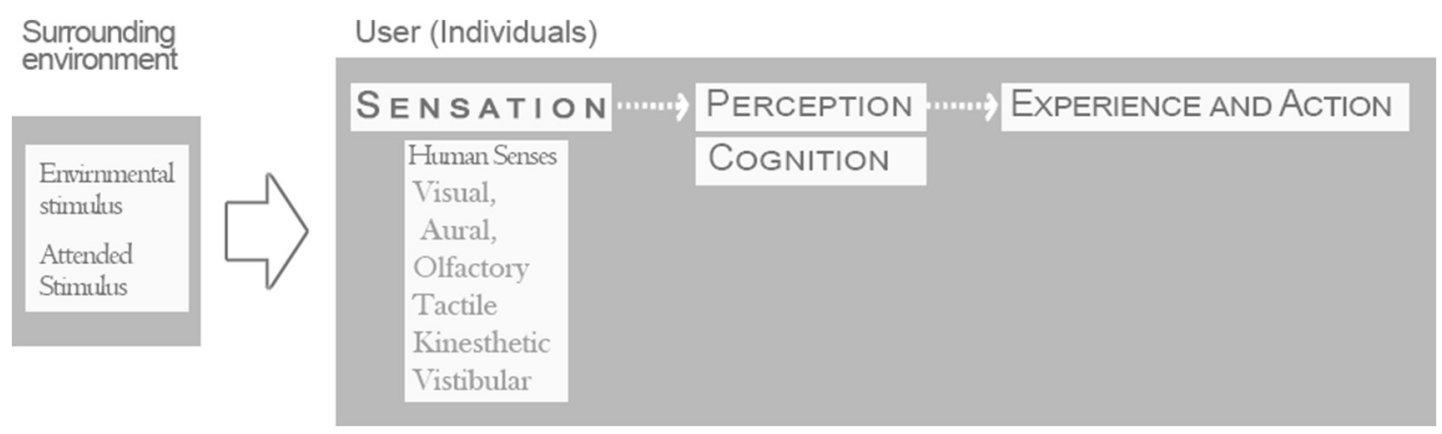

Fig. 2: showing the perceptual process stages (source: researcher)

\subsection{Sensation}

Information about the world must have a way to get into the brain, where it can be used to determine actions and responses. The way into the brain is through the sensory organs and the process of sensation, which occurs when special receptors in the sense organs (the eyes, ears, nose, skin, and taste buds) are activated, allowing various forms of outside stimuli to become neural signals in the brain. [4] The sensory modalities, such as sight, hearing, smelling and touch, play a dominating role in spatial perception of humans. Information streams from these senses are continuously integrated and processed in the brain, so that a cognitive representation of the threedimensional environment can be accurately built, whether stationary or in movement. Each of the 
six senses uses different cues for exploring the environment and features. [5] Touch, smell, kinesthesia and taste provide information on the near space, also called haptic space, while vision and hearing gather stimuli representing objects or events in the far space. Figure 3 shows the 6 senses and how the landscape elements stimulate these senses. [6]

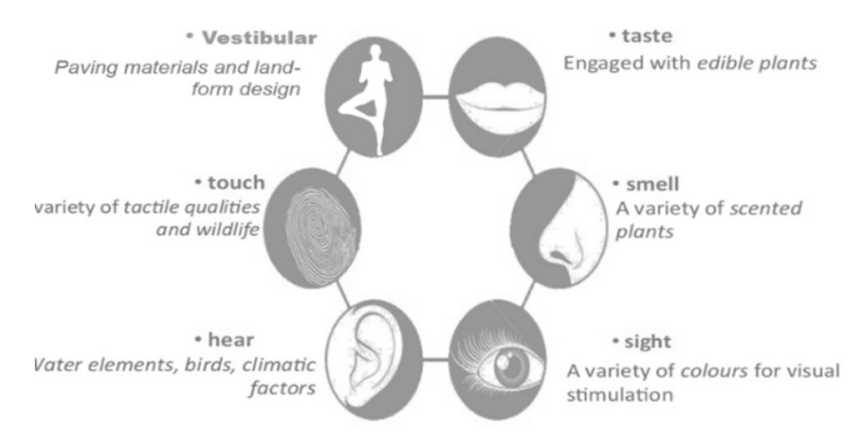

\subsection{MULTI-SENSORY ENVIRONMENT}

A multi-sensory environment is a space that helps enhance a person's cognitive and mental capabilities through various sensory stimulations and interactive experiences. This environment has traditionally been the main focus for indoor spaces in hospitals and elementary schools. However, the features and strategies found in these facilities can be combined with the landscape elements in an outdoor space to create an immersive multi-sensory outdoor environment. [7]

According to Jenkins et al. (2015), the relationship that a person has with an environment can be enhanced when there are a variety of sensory stimulations that go beyond visual aesthetics, like smelling a flower or touching an object. [8] When an environment relies on a single sense, it decreases the ability of the space to engage and welcome a diverse range of individuals, because their needs are not met in the space (Jenkins et al., 2015). In contrast, figure 4 shows how an environment could engage a variety of people. [9] For example, an individual with low to no vision would not be able to navigate a park that had no signs, and limited textured pathways, unlike a sighted person would have. This is the first aim of a multi-sensory space. Another aim is that it enriches the users' cognitive and physical abilities through the interaction with different sensory spaces. Moreover, the sensory space is also designed to balance between the mental, physical, and social facilities. A multifunctional space should provide a balanced sensory experience that does not exclude a group of people from using the space. [7]

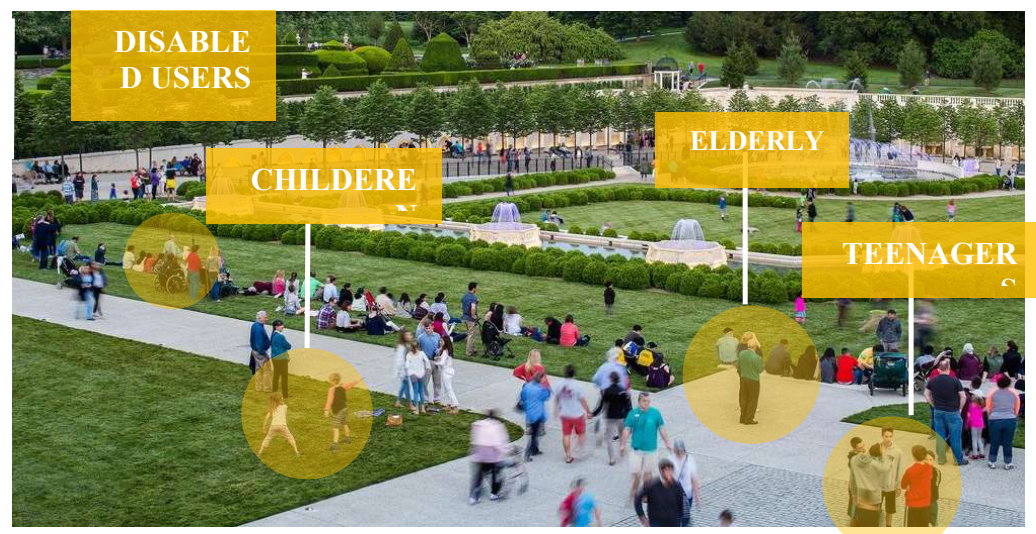

Fig. 4 showing the diversity of the users due to the diversity of the landscape elements therefore diversity of the 


\subsection{DESIGNING PLANES AND LANDSCAPE ELEMENTS}

This section illustrates the relationship between design planes that form the space and landscape elements. Within each design plane, the landscape architect inventively uses and integrates the landscape elements, namely landform, vegetation, water elements, built structures and furniture, as in figure 5. These major landscape design elements, both individually and collectively, create outdoor spaces by affecting the ground plane, vertical plane and overhead plane. [10] These elements can be thought of as a basic palette of spatial design. How they are designed and integrated depend on the user's cultural, social, political, economic and environmental needs. [11] Starting with the overhead or sky plane, it is created by: furniture elements in the landscape such as pergolas, plant elements such as the bottom of the tree canopies, or even the sky as a natural element. This plane influences the amount of skylight entering the space, as well as the perceived scale of the space where the user is found. [11]

Vertical planes create the outdoor walls, enclose the space, and serve as a backdrop to enhance other elements within the space. Vertical elements frame certain views, both inside and outside the space, playing an important role in controlling the user's visual scale and views. The plane is established by such landscape elements as: the built structures like walls and fences, and plant elements like the foliage mass of trees and shrubs. Wall plane is the most dominant plane in the formation of the user's sense of enclosure. [11]

The ground plane, the main focus of the paper, functions as the floor of the landscape. Examples include lawns, patios, terraces, decks, and walkways. This plane influences the route by which people move through the landscape and experience it. Pavement, water and vegetative surfaces, such as lawns, ground covers or low shrubs, are all different elements that may be integrated into the ground plane to achieve various design objectives. [12]

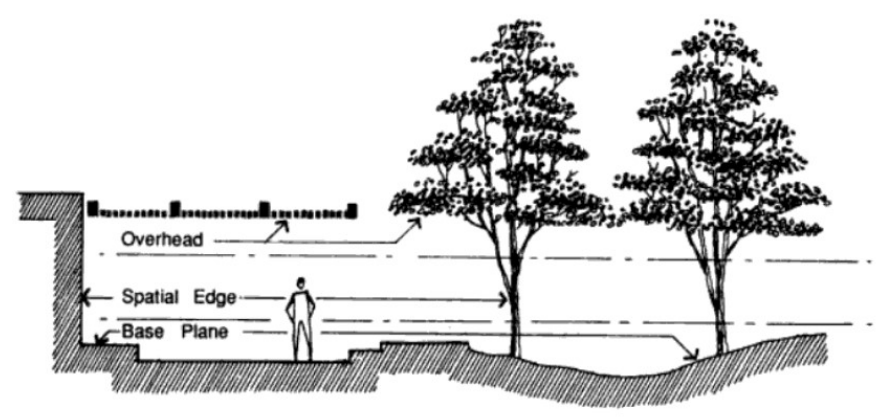

Fig. 5 shows some of the elements forming each plane (source: [12])

\subsection{LANDFORM}

Landform is the most important and essential element in landscape architectural design. This is because the effect of gravity means that human beings consistently seek to create flat or horizontal spaces for many uses, and activities for experiencing the surrounding environment, including a wide range of social, cultural and recreational activities. Landform has three main properties acting as stimuli perceived by the users. The first is the type of the landform. The level landform is static, non-moving, and in balance with the earth's gravitational forces, making users feel comfortable and surefooted when standing on or walking across a level landform. The sensory stimuli having impact on users experiencing level landform affect the visual sense, due to the openness, and the kinesthesia sense, due to the stability and the neutrality. The other landform types are the convex landform and the concave landform. Like the level landform, both stimulate the visual and 
kinesthesia senses of the human, but each type of landform stimulates the senses with different stimuli giving a variation in users. The second variable is the steepness of the slope, where the slope is the sides of the landform. As the steepness of the slope increases, it acts as a vertical plane for the space. This case happens in the concave landform, and this is how the visual sense of the user is affected. The form is the third and last property. In the landform, users frequently need to move from one space to another, and in many cases these spaces may be on different levels. Steps and ramps are the two elements used to achieve this. These two forms impact the kinesthesia sense, while the visual sense is influenced by the pattern of lines created by steps. In contrast, the most important advantage of ramps, compared to steps, is that they permit freedom of movement through the environment for most potential users. However, that some people find ramps more difficult to walk on, because of the sloped surface. This is also referred to the kinesthesia sense. [13] Figure 6 shows the 3 main stimuli stated above and the senses stimulated.

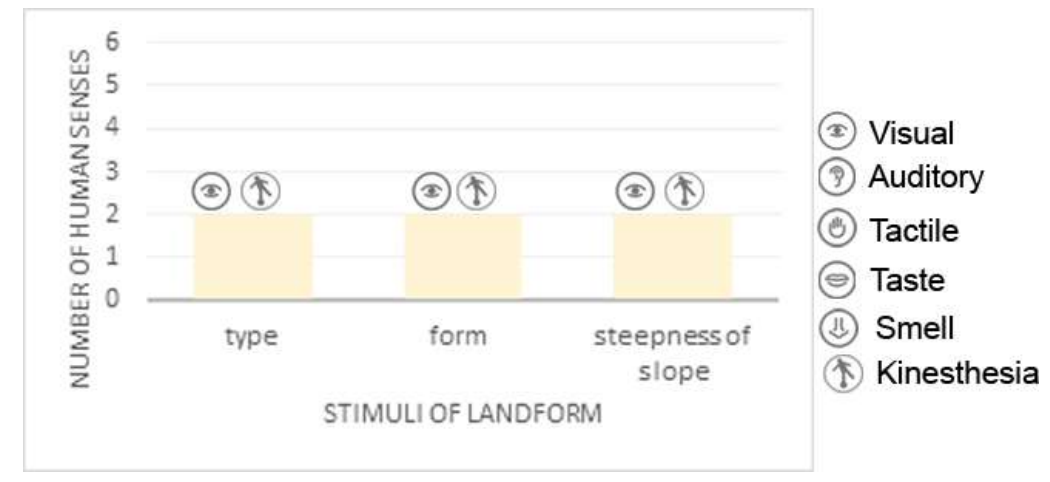

Fig. 6 shows the human senses and the number impacted by the different landform stimuli (source: researcher)

\subsection{HARD GROUND SURFACES (PAVEMENT)}

Pavement is any hard natural or artificial surface material consciously placed on the ground plane of an outdoor space to establish a durable surface, while also satisfying design objectives. [14] Hard pavement surfaces must be designed to serve all types of users. For example, the right material, texture, scale, and pattern should be chosen, and must be integrated with each other and with the surrounding surfaces according to the function of the space. [15] Pavement material is the first property of the pavement. There are countless pavement materials available in the landscape design. Generally, they fall into three major groups: loose pavement such as gravel, unit pavers such as brick, tile, or stone, and adhesive pavement as in Portland cement concrete or asphalt. [16] Each of these categories acts as a stimulus to the visual, kinesthesia, auditory and tactile sense. Color may be the only pavement property that impacts only one sense, namely the visual senses [17].The speed of users, which is related in some way to the kinesthesia sense, may be more enhanced by the third property, which is the texture of the pavement. For example, a rough pavement in the wider area of the walkway ensures that rapid movement in this space is difficult, making the user move slowly and experience the space around. While in narrower spaces, a smooth pavement may be used to accommodate easier and fast movement. In addition, the pavement texture enhances the visual and tactile sense of the users. [14] A distinct pavement pattern not only influences the visual sense, but can also create a strong sense of place. [18] The pavement could suggest a stationary experience to the user by creating a space with a non-directional, static pavement pattern. This influences the kinesthesia sense of the users. Scale of pavement or walkways in public parks may be seen from more than one aspect: the length of the walkway, its width, as well as the distance between the blocks forming this pavement or walkway. Each of these variables has a direct impact on the multi- 
sensory experience of the users, whether on the kinesthesia sense or the visual sense, as shown in figure 7.

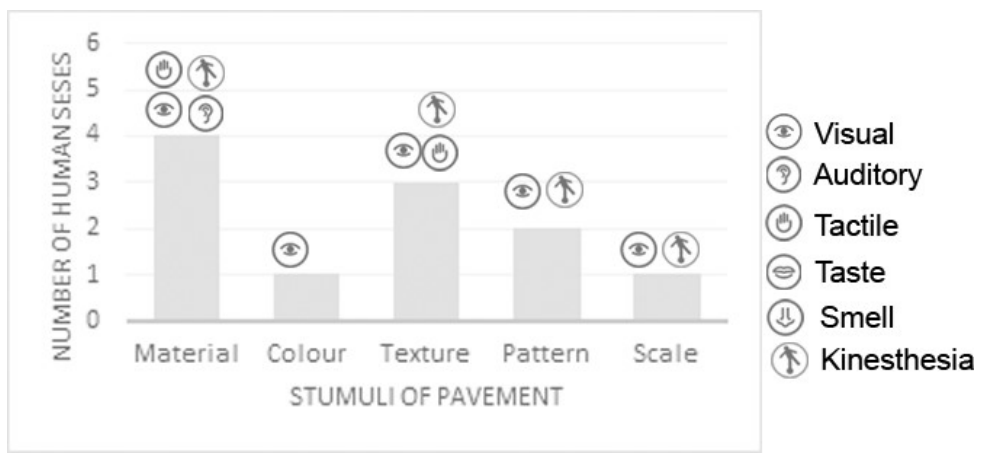

Fig. 7 shows the human senses and the number impacted by the pavement stimuli (source: researcher)

\subsection{SOFT GROUND SURFACES (PLANTS)}

Plants are another extremely important landscape physical element in the design of outdoor environments. Along with other landscape elements, plant constitute the major components used by landscape architects in designing open spaces, such as public parks, as they provide a touch of beauty and natural life in an environment [14]. The four main stimuli of plants impacting users are the type, size, color and texture, as shown in figure 8. Plant type is the first property of the plants that enriches and stimulates the multi-sensory experience of users. Ground cover is the first type, one of the major advantages of many ground covers over grass is that they are colorful and decorative enhancing the visual sense. Lawn is one of the basic elements of park design acting as a natural green carpet of outdoor spaces. The other senses influenced by the type of plant, whether lawns or ground covers, are the tactile and the auditory sense [19]. Plant size is another plant property influencing the users' experience. The two stimuli of this property are the plot area and the height of the plant. In general, ground cover and grass lawns help in defining a space and enhance the kinesthesia senses. It gives the user's visual continuity to the rest of the space without blocking the visual senses. [14] [20]. Color is the third property of plants. The colourful ground cover is a seasonal plant allowing the user to sense the time of the surrounding environment due to its variation of colour over the year as the seasons change. While the grass lawn acts as a unifing ground plane for all other landscape elements due to its one unique colour. Both the ground cover and the lawn colours have great impact on the visual sense.The texture of the plant helps it to function differently in different places, a common use of the ground cover is to define a nonwalking surface, especially when opposed to lawn or pavement, due to its rough texture. On the other hand, this distinct rough texture stimulates the visual sense for users experience [14] Just like the ground cover, the different texture of the grass lawn helps it to outline a desired shape on the ground, but contrary to the ground cover, the smooth and soft texture of the grass lawn encourages users to walk on it experiencing and enjoying it through their tactile sense. 


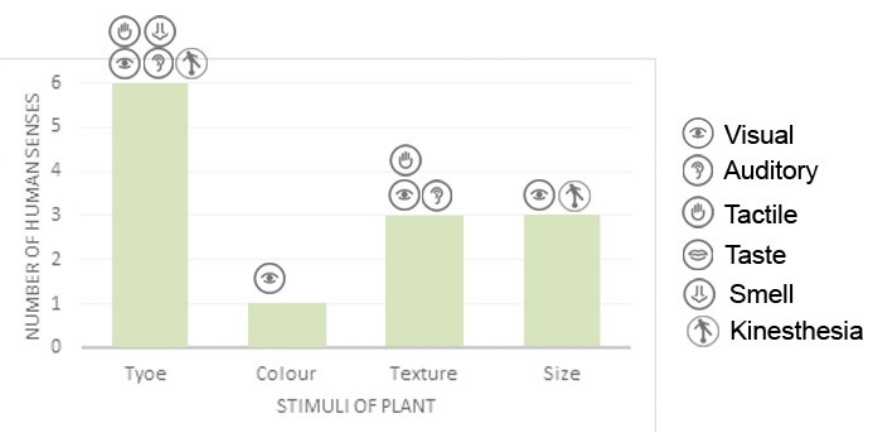

Fig. 8 shows the human senses and the number impacted by the plant stimuli (source: researcher)

\subsection{WATER}

Water is another physical design element used by landscape architects in the design of outdoor environments. Water type is mostly categorized according to its motion. There are generally two types of water, static, which is quiet and non- moving, and dynamic, which is continuously moving and changing. Static water is generally found in lakes, ponds, pools, or gently flowing rivers. Static water quality is visually placid. This quality generates visual stimuli that encourage the user to experience a peaceful and relaxing surrounding environment, and the mind to think uninterruptedly. [14] Dynamic water is found in rivers, streams, waterfalls and different types of water jets. Unlike static water, dynamic water has a direct impact on the visual and the auditory sense, due to the continuous movement of water and its collision with a fixed object or with different surfaces of different types. In some cases, dynamic and static water have an impact on the tactile sense, when designed to be stepped on by the users. In most cases, the water form is determined by the characteristics of the container. Therefore the same volume of water could have an infinite number of different forms. [14] Water plays a role in space organization according to its form as a closing element, because it has a great impact on the kinesthesia sense of the users as the person must walk around instead of passing through, and this is determined by the regularity and the irregularity of the water form. [21] Water size is meant to be the container size that contains the water, in other words the length, width and the height of this container or the water feature. The length and width of the water feature directly impact the kinesthesia sense of the user, as they control the movement, as they act as an edge for the pathways. The depth of the container impacts the visual sense, due to the visual stimuli emitted from the type of bottom of the water container. [17] All the stimuli and the senses engaged are shown in figure 9.

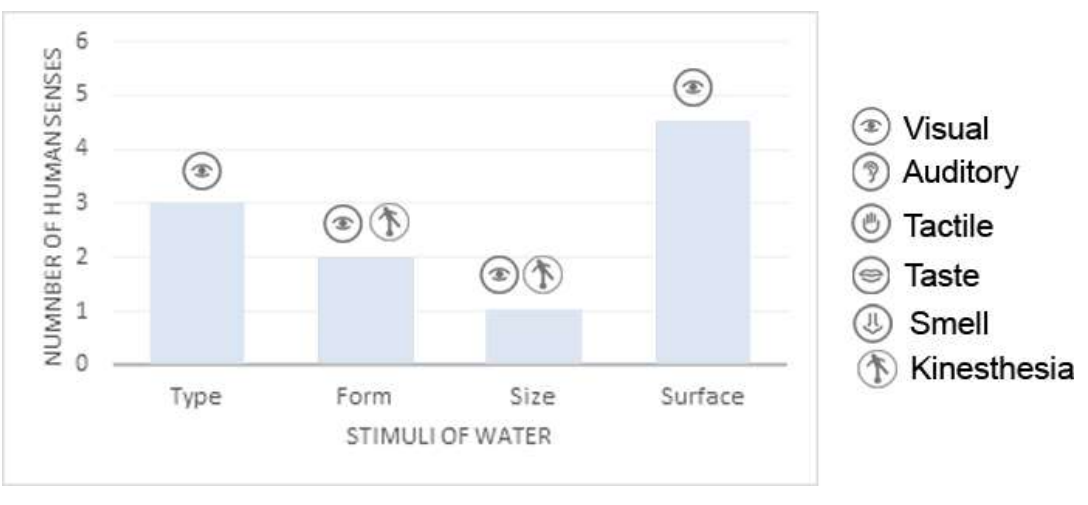

Fig. 9 shows the human senses and their number impacted by the water stimuli (source: researcher) 
Table 1 summarizes the relation between the three constituents forming the framework, namely the landscape elements, the stimulus generated from each element, and the senses engaged by each stimulus.

\begin{tabular}{|c|c|c|c|c|c|c|c|c|c|c|c|c|c|c|c|c|}
\hline \multirow{2}{*}{$\begin{array}{l}\text { LANDSCAPE } \\
\text { ELEMENTS } \\
\text { PROPERTIES } \\
\begin{array}{l}\text { HUMAN } \\
\text { SENSES }\end{array}\end{array}$} & \multicolumn{3}{|c|}{ LANDFORM } & \multicolumn{5}{|c|}{ PAVEMENT } & \multicolumn{4}{|c|}{ PLANT } & \multicolumn{4}{|c|}{ WATER } \\
\hline & type & Form & steepness & material & colour & texture & pattern & scale & type & colour & texture & size & type & form & size & surface \\
\hline Visual & $*$ & * & $*$ & $*$ & $*$ & $*$ & * & $*$ & $*$ & $*$ & * & * & $*$ & $*$ & $*$ & $*$ \\
\hline Auditory & & & & $*$ & & $*$ & & & * & & $*$ & & $*$ & & & $*$ \\
\hline Tactile & & & & $*$ & & $*$ & & & $*$ & & $*$ & $*$ & $*$ & & & $*$ \\
\hline (II) & & & & & & & & & $*$ & & & & & & & \\
\hline () & & & & & & & & & & & & & & & & \\
\hline Kinesthesia & & & & * & & & $*$ & & $*$ & & & & & $*$ & & \\
\hline
\end{tabular}

\section{FINDINGS AND RESULTS}

After studying the multi-sensory perceptual processes and how the user perceives the surrounding environment and landscape through the six senses mentioned above, the landscape elements were studied, specifically the elements that form the ground plane, as well as the stimuli of each landscape element influencing the user's experience. The next step, as shown in figure 10, would be to validate what the researcher concluded by conducting a survey which assesses the user's awareness of the elements, the properties of each landscape element, and the importance of these elements on their multi-sensory experience in public parks. Validation of the framework will be done by comparing it to the results of this survey.

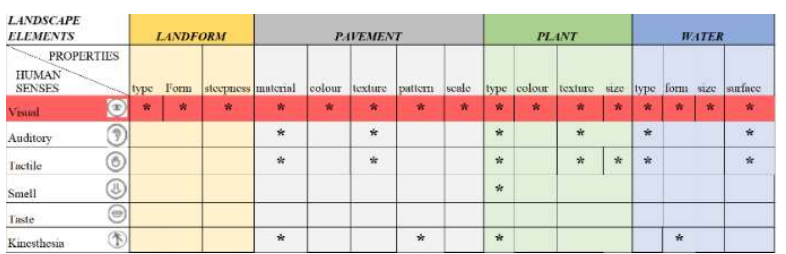

\section{QUESTIONNAIRE}

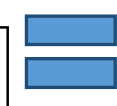

\section{VALIDATED FRAMEWORK AND GUIDELINES}

Fig. 10 shows steps for validating the framework (source: researcher)

This survey comprises a group of respondents of 174 individuals in Alexandria, Egypt, among which are 45 male and 129 female respondents of different age groups. The graphs below show the demographics of the respondents. After asking users about their frequency of visiting public parks, it was found that the user's frequency has increased as the COVID-19 pandemic has dramatically changed the schemes, priorities and frequencies of activities practiced on a daily basis, including the preference of staying outdoors more often. This ensures that the design of all open spaces, including public parks must be reconsidered for giving the users the opportunity to experience the space the best way it could be.

\subsection{LANDSCAPE ELEMENTS RANKING}


The user is a main factor that must not be neglected when forming the framework. Therefore, results conducted from the survey were divided into two variables. The first is the senses that are stimulated by each landscape element, which are shown figure 11. The ranking was as follows: the first landscape element was the plant with 5 senses impacted, second was the water with 3 senses and the landform and pavement each with 2 senses stimulated. The second is the significance of the landscape elements in their engagement in the user's experience in public parks. The users were asked to state the level of importance of each landscape element from their own point of view and the results were as shown in figure 12 below.

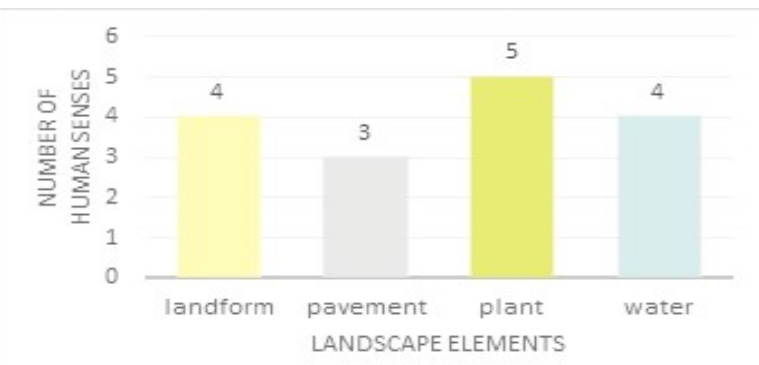

$\mathrm{T}$ : Fig.11 shows the first variable, which is the number of human senses each landscape element engages (source: researcher)

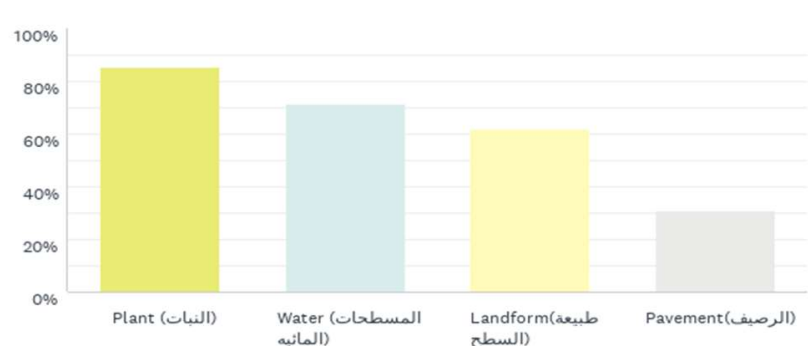

$\mathrm{d}$ the ques researcher
Fig. 12 shows the percentages of respondents voting for the importance and significance of each element (source: researcher)

\begin{tabular}{|c|c|c|c|c|c|c|}
\hline \multirow{11}{*}{$\begin{array}{l}\text { Landscape } \\
\text { elements }\end{array}$} & Variable (perspectives) & Elements & From literature & \multicolumn{2}{|c|}{$\begin{array}{c}\text { From } \\
\text { questionnaire }\end{array}$} & Rankings \\
\hline & \multirow{5}{*}{$\begin{array}{c}\text { In terms of significancel } \\
\text { engagement in } \\
\text { perception of users }\end{array}$} & & & \multicolumn{2}{|c|}{ Percentages } & \\
\hline & & Landform & - & 61.85 & 89.02 & 3 \\
\hline & & Pavement & - & 31.21 & 77.91 & 4 \\
\hline & & Plants & - & 85.55 & 98.84 & 1 \\
\hline & & Water & - & 71.68 & 76.88 & 2 \\
\hline & \multirow{5}{*}{$\begin{array}{l}\text { In terms of number of } \\
\text { human senses engaged }\end{array}$} & & Number of senses & \multicolumn{2}{|c|}{ Number of senses } & \\
\hline & & Landform & 2 & \multicolumn{2}{|c|}{4} & 4 \\
\hline & & Pavement & 4 & \multicolumn{2}{|c|}{3} & 3 \\
\hline & & Plants & 5 & \multicolumn{2}{|c|}{5} & 1 \\
\hline & & Water & 4 & \multicolumn{2}{|c|}{4} & 2 \\
\hline
\end{tabular}

Therefore, according to results from both literature review and questionnaire analysis, the following order of landscape elements (as shown in table 2) can be concluded. This is according to the two variables mentioned before, which are the significance of the element and the number of senses stimulated by each element.

1.Plants ranked first in both variables, meaning that it is obligatory that any public park must have variation in plants, as it is the most significant element for the users, engages all the senses and provides the aspect of life in the landscape.

2.Water ranked second in both variables after plants. Therefore, the complexity of water elements is required when designing sensory public parks, as it is a significant element perceived by the users and creates a rich sensory experience. 
3. Pavement is an important element that any open space cannot be without, but from the user's point of view, it ranked fourth in its significance, and third in the number of senses engaged, as it engages from 3- 4 senses.

4. Landform is the element that comprises all the other landscape elements. In contrast with the pavement, it ranked third in the significance, and fourth in the number of human senses, as it engages between 2-4 senses.

\subsection{LANDSCAPE ELEMENTS STIMULUS RANKINGS}

Stimulus, as studied before, is anything physical in the surrounding environment perceived by the users that stimulates the human senses. It refers to what is out there in the environment, what users actually pay attention to, and what stimulates the sensory receptors. The world is full of stimuli existing in both the environment and within the person's body that can attract our attention through various senses. In this research, the stimulus is produced from the landscape elements in the public parks. These stimuli were studied in terms of the human senses they stimulate. Therefore, the number of senses each stimulus triggers gave the first variable. The second variable is the significance of each stimulus to the users. Figure 13 below shows the order of stimuli of each landscape element. This order refers to the significance of stimuli in the users perceptual process, meaning that the more significant the stimulus is, the more it is essential in designing the public park. This order was made according to the number of respondents voting for each stimulus. The other variable was the number of human senses stimulated by the landscape element, as it was indicated in the literature review.

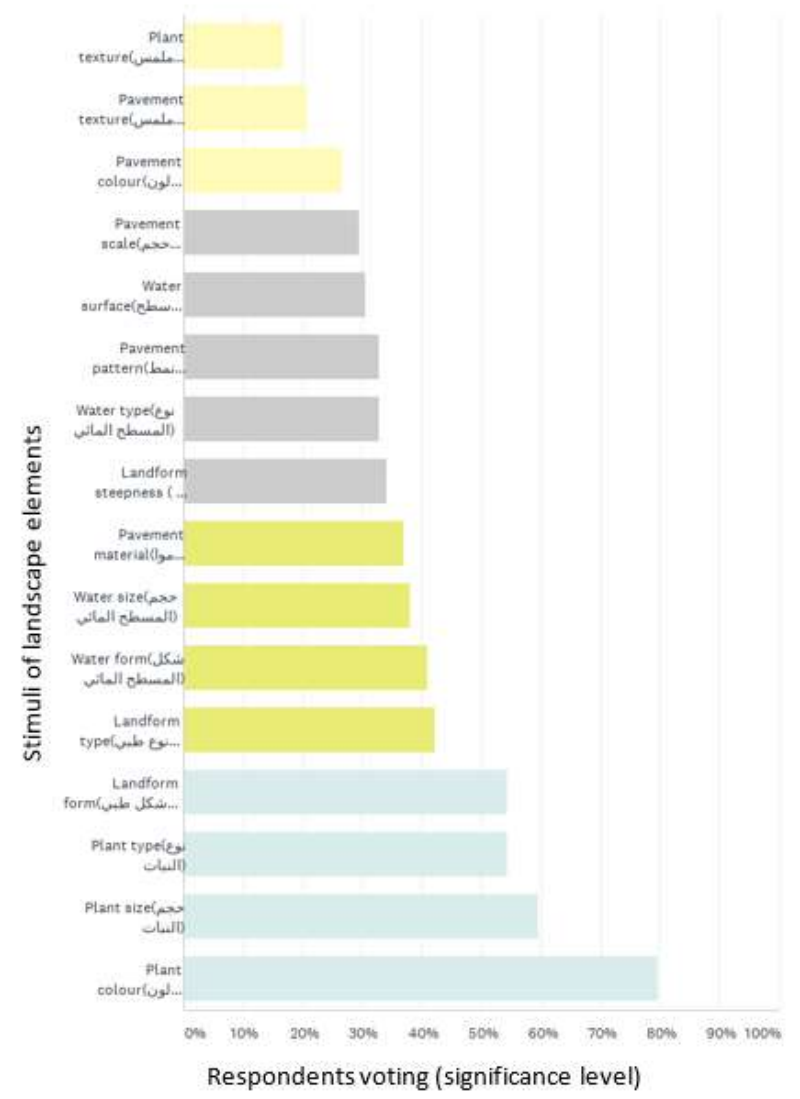

Fig. 3.13 showing the significance of each stimuli according to the users (source: researcher) 


\section{SJFA}

Table 3 shows the three components of the framework, namely the human senses, the landscape elements and the stimuli relations, along with the number of senses, and the significance percentage of each stimulus. This was converted into categories: the first was related to the number of senses the stimulus engages. From three to six senses was categorized as high, while the stimulus that engaged from one to three senses was categorized as low. The same thing was done to the second variable, the significance of each stimulus. The stimulus that is within the range of $50 \%$ to $100 \%$ is categorized as high, while the stimulus that lies from $0 \%$ to $50 \%$ is categorized as low. This categorization is shown in figure 14.
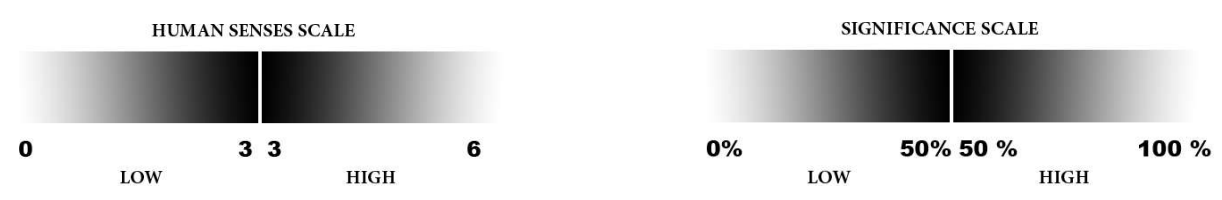

Fig.14 shows the scales reached to categorize the landscape elements stimuli according to: the number of senses (left) and the significance of each stimulus (right) (source: researcher)

Table 3 shows the developed framework showing the number of senses and the significance of each stimulus (source: researcher)

\begin{tabular}{|c|c|c|c|c|c|c|c|c|c|c|c|c|c|c|c|c|}
\hline & \multicolumn{4}{|c|}{$\begin{array}{l}\text { Soft ground } \\
\text { surfaces } \\
\text { (Plants) }\end{array}$} & \multicolumn{3}{|c|}{ Landform } & \multicolumn{5}{|c|}{$\begin{array}{l}\text { Hard ground surfaces } \\
\text { (pavements) }\end{array}$} & \multicolumn{4}{|c|}{$\begin{array}{l}\text { Horizontal water } \\
\text { bodies }\end{array}$} \\
\hline & $\mathfrak{E}_{\mathbb{N}}^{\mathbb{N}}$ & $\frac{\substack{0 \\
0 \\
0}}{0}$ & 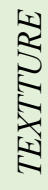 & $\frac{\sqrt[1]{N}}{\sqrt{2}}$ & $\stackrel{1}{\hbar}$ & 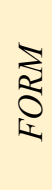 & 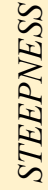 & $\underset{\mathbb{Z}}{\mathbb{E}}$ & 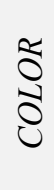 & है & 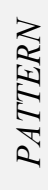 & 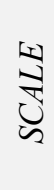 & $\frac{1}{2}$ & 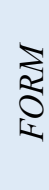 & $\frac{\sqrt[1]{N}}{\sqrt{5}}$ & 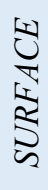 \\
\hline Visual & $*$ & $*$ & $*$ & $*$ & $*$ & $*$ & $*$ & $*$ & $*$ & $*$ & $*$ & $*$ & $*$ & $*$ & $*$ & $*$ \\
\hline Auditory & $*$ & & $*$ & & & & & * & & $*$ & & & $*$ & & & $*$ \\
\hline Tactile & $*$ & & $*$ & $*$ & & & & $*$ & & $*$ & & & $*$ & & & $*$ \\
\hline Smell & $*$ & & & & & & & & & & & & & & & \\
\hline Taste & & & & & & & & & & & & & & & & \\
\hline Kinesthesia & $*$ & & & $*$ & $*$ & $*$ & $*$ & $*$ & & & $*$ & & & $*$ & $*$ & \\
\hline
\end{tabular}

\begin{tabular}{|c|c|c|c|c|c|c|c|c|c|c|c|c|c|c|c|c|}
\hline $\begin{array}{c}\text { Number of } \\
\text { senses }\end{array}$ & 5 & 1 & 3 & 2 & 2 & 2 & 2 & 3 & 1 & 3 & 2 & 1 & 3 & 2 & 2 & 3 \\
\hline $\begin{array}{c}\text { Significancel } \\
\text { engagement }\end{array}$ & $\begin{array}{c}54.3 \\
4\end{array}$ & $\begin{array}{c}79.7 \\
7\end{array}$ & $\begin{array}{l}16 . \\
76\end{array}$ & $\begin{array}{c}59.5 \\
4\end{array}$ & $\begin{array}{c}42.2 \\
0\end{array}$ & $\begin{array}{l}54 . \\
34\end{array}$ & $\begin{array}{c}34.1 \\
0\end{array}$ & $\begin{array}{c}36.9 \\
9\end{array}$ & $\begin{array}{c}26.5 \\
6\end{array}$ & $\begin{array}{c}20.8 \\
1\end{array}$ & $\begin{array}{l}32 . \\
95\end{array}$ & $\begin{array}{l}29 . \\
48\end{array}$ & $\begin{array}{c}32.9 \\
5\end{array}$ & $\begin{array}{l}41 . \\
04\end{array}$ & $\begin{array}{l}38 . \\
15\end{array}$ & $\begin{array}{l}30 . \\
64\end{array}$ \\
\hline
\end{tabular}

\section{CONCLUSION}

Landscape affects not only visual stimuli, but also other senses such as tactile, taste, smell, auditory and kinesthesia senses. After studying all the landscape elements that have direct impact on the multi-sensory experience of the users, a set of stimuli were concluded for each landscape element based on the study. 
The user is the main factor in evaluating any experience and must not be neglected. Therefore, the questionnaire was done to complete and validate the framework, because the perception of users differs according to different factors, namely individual factors, such as age and gender, cultural factors, and physical factors.

The plant and water elements are two important landscape elements as they were ranked the same in the two variables: the number of senses engaged by each landscape elements, and their significance according the user's point of view. They were followed by the landform and pavement elements.

As for the stimuli the type of the plants used in the design is an important thing to be considered in the design as it engages high number of human senses and at the same time it is significant by the user and the pavement material is another important stimulus to be engaged in the design. For evaluating or designing any outdoor space such as public this framework could act as a guide

\section{REFERENCES:}

[1] K. Lynch, The Image of the City, Massachusetts Institute of Technology Cambridge, Massachusetts, and London, England, 1960.

[2] E. B. Goldstein, Sensation and Perception, Linda Schreiber, 2010.

[3] E. van Heijgen, "Human landscape perception Report on understanding human landscape perception and how to integrate and implement this in current policy how to integrate and implement this in current policy," Wageningen ur for quality of life, Wageningen, Netherlands, 2010.

[4] M. Dischinger, "Designing for all senses, Accessible spaces for visually impaired citizens," Department of Space and Process school of Architecture Chalmers University of Technology, Sweden, 2000.

[5] A. W. D. Ł. Ł. Magdalena Szczepańska, "Non-visual perception pf landscape - use of hearing and other senses in the perception of selected spaces in the city of Poznan," Teka Kom. Arch. Urb. Stud. Krajobr. OL PAN, Poznan, Poland, 2013.

[6] P. Hadjiphilippou, "The contribution of the five human senses towards the perception of space," Department of architecture University of Nicosia, Cyprus, 2013.

[7] M. Diep, "Multisensory environments and student wellness on urban campuses, Co-designing an Inclusive Space at Butterfield Park to Help Support Student Mental Health," OCAD University, Toronto, Ontario, Canada, 2019.

[8] H. Hussein, "Sensory Garden in Special Schools: The issues, design and use," Research gate, Kuala Lumpur, Malaysia, 2009.

[9] C. P. P. B. M. Howard-Brooks, "The Healing Circle - As sensory garden for all abilities," Barwon Community Leadership Program, 2011.

[10] N. M. N. Z. A. Z. O. Hazreena Hussein, "Engaging Research and Practice in Creating for Outdoor Engaging Research and Practice in Creating for Outdoor," Procedia social and behavioral sciences, Kuala Lumpur, Malaysia, 2013. 
[11] C. Dee, Form and fabric in landscape architecture, New York: Spoon press, 2001.

[12] J. L. Motloch, Introduction to landscape design, New York: John Wiley and sons, inc, 2001.

[13] D. Rodman, "Universal Design Guidelines for Outdoor Spaces: Plan and Design for Choice," City of Pitt Meadows and the District of Maple, Pitt Meadows, Canada, 2009.

[14] N. K. Booth, Basic elements of landscape architectural design, Ohio: Elsevier Sciencc Publishing, 1985.

[15] Karl B Lohmann, Fundamentals of landscape archtiecture, Scranton, Pennsylvania: International Correspondence Schools, Scranton, Pennsylvania , International Correspondence Schools, Canadian Ltd., Montreal, Canada, 1963.

[16] J. Gibbons, "Pavements and surface materials," Nonpoint education for municipal officials, Ecuador, 1999.

[17] L. J. Hopper, Landscape Architectural Graphic standards, New jersey: John Wiley and sons, inc, 2007.

[18] J.-P. M. Egbert BEUVING, "Pavement surface materials used in urban areas," Session 4 - Specific techniques and innovations, Krakow, Poland, 2005.

[19] C. K. Sahin, "Lawns and Ground Covers in Landscape Design," in Advances in landscape Architecture, Turkey, Intech Open, 2013.

[20] L. De, "Lawn grasses - A review," International lournal of horticulture, Pakyong, India, 2017.

[21] D. G. Ö. Tugba Duzenli, "Purposes of Waterscapes Usage in Landscape Architecture," Research Gate, Trabzon, Turkey, 2016.

[22] K. HUDSON, "Cladfeaturesfor architects, designers, investors \& developers," Cybertrek, 2018. [Online]. Available: https://www.cladglobal.com/architecture-designfeatures ?codeid=32487\& source=home \&p=9. [Accessed 10 September 2020]. 


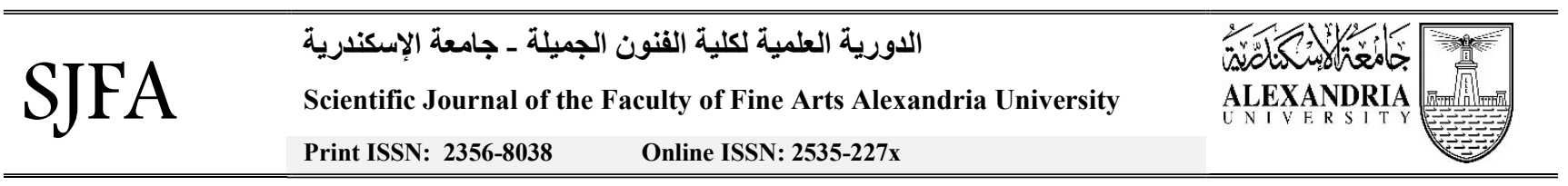

\section{نحو اطار مرجعي لتقييم عناصر تنسيق الموقع ذات التاثيرات الحسية المتعددة}

$$
\text { فريده رجب3 ، علاء الدين سرحان } 1 \text { ياسر فر غلي2 }
$$

الاماكن الفتوحة ليست مجرد اماكن يتردد عليها الناس فقط بل هي اماكن يمارس بها الناس العديد من انشطتهم اليومية و

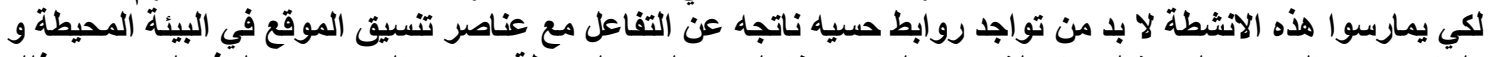

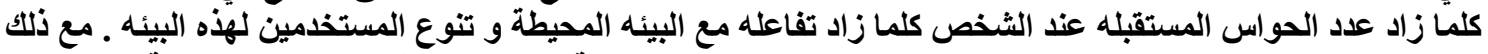

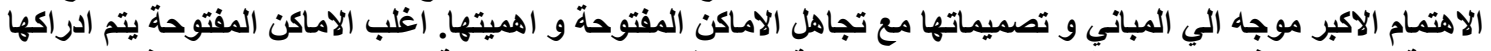

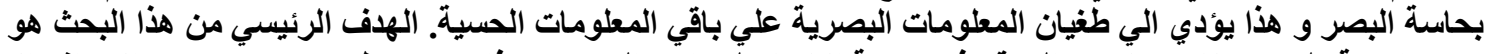

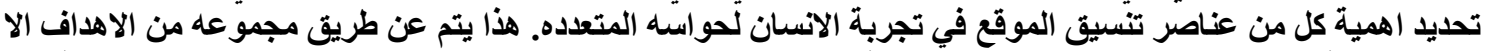

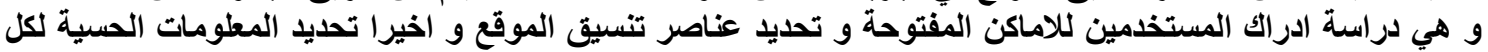
عنصر و تاثير هذه المعلومات علي حواس الانسان. الكلمات الدالة: عناصر تنسيق الموقع، البيئة المحبطة ، تجربة متعددة الحواس ، المعلومات الحسية. 